\title{
Evaluation of the breeding and genetic potential of strawberry varieties and hybrids based on economically valuable traits
}

\author{
V.I. Lapshin ${ }^{1, *}$, V.V. Yakovenko ${ }^{1}$, and S.N. Shcheglov ${ }^{2}$ \\ ${ }^{1}$ Federal State Budget Scientific Institution "North Caucasian Federal Scientific Center of \\ Horticulture, Viticulture, Wine-making", 40 Let Pobedy Str., 39, 350901 Krasnodar, Russia \\ ${ }^{2}$ Federal State Budgetary Educational Institution of Higher Education "Kuban State University", \\ Stavropolskaya Str., 149, 350040 Krasnodar, Russia
}

\begin{abstract}
The study of the inherited features of the genotype and the directions of variability of breeding-valuable traits of strawberry varieties and hybrid forms is an integral part of most researches in the field of this crop breeding. The purpose of this work was to determine the most promising strawberry varieties and hybrid selections by a complex of economically significant characteristics based on the assessment of their selection and genetic potential. In the period 2018-2020, 7 varieties and 17 inter-variety hybrids of strawberry were studied. Using methods of multivariate mathematical statistics, including calculation of factor contributions, estimation of principal components, and cluster analysis of the hierarchical algorithm using the Ward method, the variability of strawberry genotypes in terms of crop structure and quality was estimated. It is shown that variety genotype makes a decisive contribution to the variability of the studied forms. The model of the ideal variety was used as a comparative criterion for promising varieties and hybrid selections. As a result of clustering and combining the studied forms in the intervals of Euclidean distances, a high assessment was made for the selection and genetic potential of strawberry varieties Onda, Belrubi, Florence and Nelli, as well as hybrid forms with their participation.
\end{abstract}

\section{Introduction}

Knowledge of the genotypic value of the parent forms and their hybrid progeny on the basis of productivity and berry quality determines the success of the breeding work for the strawberry crop. Currently, most of the selection and genetic studies are devoted to the assessment of the genetic potential of the original parental forms [1-3].

Indicators of strawberry productivity and quality are determined by the genetic characteristics of the varieties and the growing environment where the growth and development of hybrid progeny takes place [4-6].

The need to increase the indicators of economically valuable strawberry characteristics with a pronounced ecological zoning, due to the specific adaptation of the crop, stimulates

${ }^{*}$ Corresponding author: lavai@list.ru 
the practical need for new strawberry genotypes that contribute to solving a number of problems related to the quality of berries, the adaptability of varieties, their resistance to diseases and pests [7-8].

The selection of the best strawberry genotypes based on several traits is a complex multi-level process due to a wide range of variability in quantitative economic and biological traits due to the octoploid nature of the genotypes and their heterozygosity, which makes it difficult to select promising forms.

Recently, a number of studies have been devoted to the study of the breeding and genetic potential of varieties and hybrids of garden strawberry based on the analysis of the variability of the complex of economic and biological traits, which considered the issues of the proximity of strawberry genotypes and the conjugacy of the studied parameters variation [9-11].

Along with traditional methods of strawberry varieties and hybrid forms evaluation, mathematical procedures of multidimensional modeling are often used simultaneously for a complex of traits, revealing linear combinations of the studied complex of traits, describing the mutual relationship of traits, as well as combining the studied objects taking into account the genotypic similarity of the studied cultivars and their hybrid progeny [12-14].

In this regard, the use of mathematical procedures for multivariate analysis based on the principal component analysis (PCA) and hierarchical cluster analysis based on the Ward method, aimed at combining information about various characteristics into a single quantitative value or graphical display, is appropriate for comparing and classifying strawberry genotypes by a set of characteristics.

Based on market trends in demand for strawberries, the need to identify varieties and hybrid forms with high yield and quality of berries increases. Therefore, the work aimed at revealing the hereditary proximity of genotypes by a set of characteristics is relevant.

The purpose of our work was to determine the most promising strawberry varieties and hybrid selections by a complex of economically valuable traits based on the assessment of their selection and genetic potential.

\section{Materials and methods}

7 varieties and 17 inter-variety hybrids of garden strawberry were studied: Nelli, Florence, Onda, Belrubi, Elizabeth II, Marmolada, Malling Pandora; 1-12-15, 11-1-15, 14-1-15, 3511-15, 35-12-15, 35-13-15 (Belrubi $\times$ Florence); 5-18-15, 5-17-15, 5-19-15 (Onda $\times$ Belrubi); 18-1-15 (Belrubi $\times$ Onda); 10-1-15 (Belrubi $\times$ Nelli); 20-1-15 (Onda $\times$ Elizabeth II); 13-1-15 (Florence $\times$ Belrubi); 5-5-08, 2-14-08 (Malling Pandora $\times$ Marmolada); 1-1-08 (Selva $\times$ Marmolada); 1-11-08 (Selva $\times$ Belrubi). In the analysis of the variability of varieties and hybrids in the period 2018-2020, 7 economically valuable traits of the berry yield and quality structure were used.

Data on the traits were taken into account in accordance with the Program and methodology of variety study of fruit, berry and nut crops.

The study of the structure of trait variability and identification of the best strawberry genotypes by a set of traits, taking into account the selection and genetic potential, was carried out using two-factor variance analysis and a number of methods of multidimensional mathematical statistics: construction and analysis of the main components, and cluster analysis by the Ward method. For statistical data analysis, a specialized manual [15] and the software package Statistica v.10 were used. 


\section{Results and discussion}

To assess the genotypic diversity of strawberry varieties and hybrid selections and the influence of the growing year on the implementation of the studied traits, we used the variance analysis with the factors "genotype" and "year", which showed a statistically significant influence of both factors and their interaction on the manifestation of all the considered traits.

At the standard values of the $\mathrm{F}$ criterion for the 5\% significance level for the factors "genotype", "year" and the interaction "genotype $\times$ year" $1.53 ; 2.99$ and 1.37, the obtained estimates of the $\mathrm{F}$ criterion for the number of berries were 28.50; 6.20 and 1.60; for maximum width of Ith order berry $-52.30 ; 5.0$ and 3.0; for height of Ith order berry $54.50 ; 4.0$ and 3.30; for average berry weight for all collections $-39.80 ; 11.70$ and 3.60; for average weight of Ith order berry $-59.20 ; 5.60$ and 3.40 ; for biological yield $-24.20 ; 10.50$ and 2.40; for berry pulp density $-120.50 ; 4.30$ and 2.50 .

It was found that the variability of economically valuable traits is mainly determined by the genotype of the studied strawberry forms, for which the share of influence in the total variance ranged from 39.6 (berry yield) to $77.4 \%$ (berry pulp density).

The small influence of growing conditions (for "year" factor from 0.3 to $2.0 \%$ of the total variance) can be explained by the preliminary careful selection of varieties and hybrids for cultivation in this climatic zone.

The study of varieties and hybrids was continued by analyzing the contributions of factors that reduce the dimension of the experimental data, while maintaining the total amount of initial information. The factor is a determinant of the complex relationship of several variation series according to field data. According to the analysis, linear combinations of the first two factors combined more than $85 \%$ of the total variability in all characteristics for the studied varieties and hybrids, which made it possible to graphically display the studied forms on the plane in accordance with the specific proximity of the genotypes to each other and to the "ideal variety" in terms of a set of characteristics (Figure 1). A hypothetical variety with the highest indicators of traits across the entire sample of strawberry varieties and hybrids was used as the "ideal" one. When evaluating the breeding and genetic potential of the studied samples, their proximity to the "ideal variety" was taken into account.

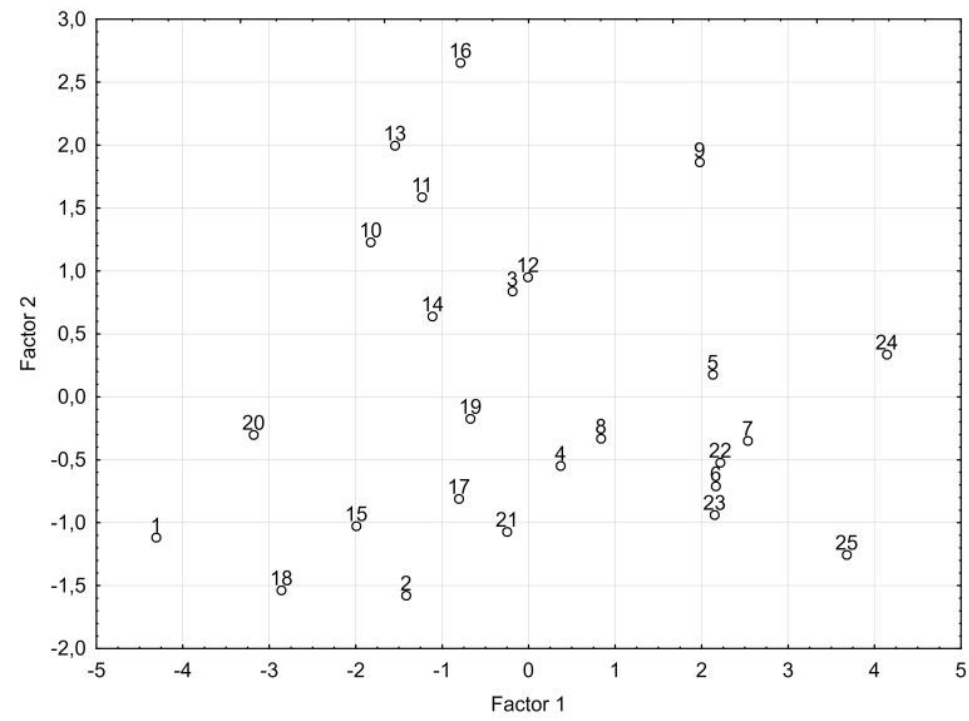

Fig. 1. Results of factor analysis of strawberry varieties and hybrids 
1 - "ideal variety"; 2-8 - varieties Nelli (2), Florence (3), Onda (4), Belrubi (5), Elizabeth II (6), Malling Pandora (7), Marmolada (8); 9-25 - hybrids 1-12-15 Belrubi $\times$ Florence (9), 11-1-15 Belrubi $\times$ Florence (10), 14-1-15 Belrubi $\times$ Florence (11), 35-11-15 Belrubi $\times$ Florence (12), 35-12-15 Belrubi $\times$ Florence (13), 35-13-15 Belrubi $\times$ Florence (14), 18-1-15 Belrubi $\times$ Onda (15), 10-1-15 Belrubi $\times$ Nelli (16), 20-1-15 Onda $\times$ Elizabeth II (17), 5-18-15 Onda $\times$ Belrubi (18), 5-17-15 Onda $\times$ Belrubi (19), 5-19-15 Onda $\times$ Belrubi (20), 13-1-15 Florence $\times$ Belrubi (21), 5-5-08 Malling Pandora $\times$ Marmolada (22), 2-14-08 Malling Pandora $\times$ Marmolada (23), 1-1-08 Selva $\times$ Marmolada (24), 1-11-08 Selva $\times$ Belrubi (25).

Based on the analysis of the correlation matrix of a set of experimental indicators, which determines the proximity of the studied objects to each other, an estimation of the quantitative contributions of factors to the overall variability was obtained using the principal component method.

It was found that further studies can use the first 4 main components that integrate $98 \%$ of the total variance of the 7 initial traits.

The combination of varieties and hybrid forms according to the calculated values of the main components, in accordance with their proximity to the "ideal variety", determined by the breeding and genetic potential, was carried out by constructing clusters according to the Ward method, according to the distribution of intra-group and inter-group variance (Figure 2).

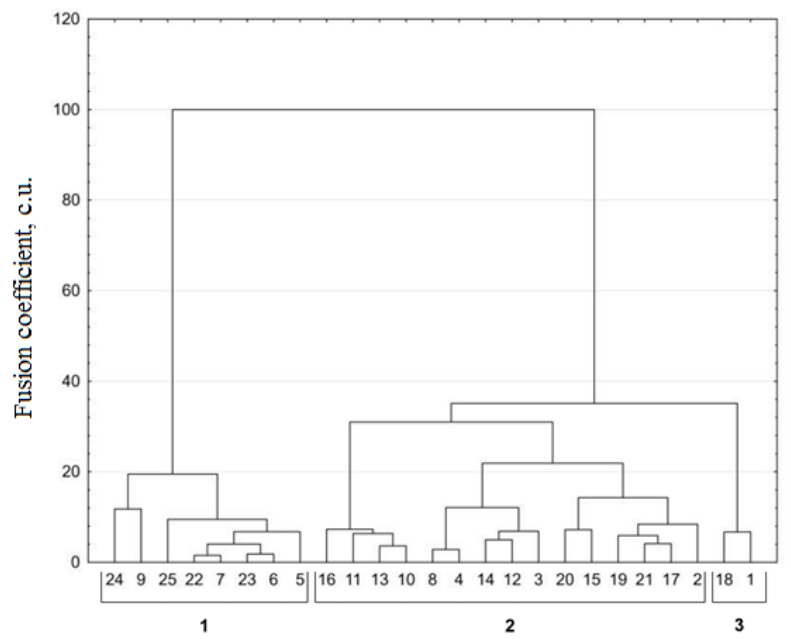

Fig. 2. Dendrite of strawberry varieties and hybrids by cluster analysis

When dividing the resulting dendrite by a fusion coefficient of 38 conventional units, 3 clusters were identified, combining varieties and hybrids:

1 ${ }^{\text {st }}$ cluster: 24 - 1-1-08 (Selva $\times$ Marmolada), 9 - 1-12-15 (Belrubi $\times$ Florence), $25-1$ 11-08 (Selva $\times$ Belrubi), 22 - 5-5-08 (Malling Pandora $\times$ Marmolada), 7 - Malling Pandora, 23 - 2-14-08 (Malling Pandora $\times$ Marmolada), 6 - Elizabeth II, 5 - Belrubi;

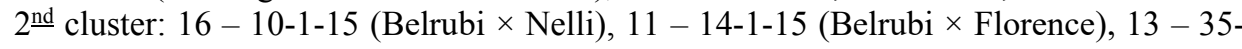
12-15 (Belrubi $\times$ Florence), $10-11-1-15$ (Belrubi $\times$ Florence), 8 - Marmolada, 4 - Onda, $14-35-13-15$ (Belrubi $\times$ Florence), $12-35-11-15$ (Belrubi $\times$ Florence), 3 - Florence, $20-$ 5-19-15 (Onda $\times$ Belrubi), 15 - 18-1-15 (Belrubi $\times$ Onda), 19 - 5-17-15 (Onda $\times$ Belrubi), 21 - 13-1-15 (Florence $\times$ Belrubi), 17 - 20-1-15 (Onda $\times$ Elizabeth II), 2 - Nelli;

$3^{\text {rd }}$ cluster: $18-5-18-15$ (Onda $\times$ Belrubi), 1 - "ideal variety".

The verification of the statistical correctness of clustering using variance analysis based on the initial values of the traits showed the reliability of the influence of the "cluster" 
factor for all the traits used in the construction of the main components. At the standard value of the $\mathrm{F}$ criterion of 3.44 for the $5 \%$ significance level, the obtained values of this criterion ranged from 5.20 to 49.0. The taken-into-account share of the factor's influence in the variance values for individual characteristics was in the range from $33.7 \%$ (number of berries) to $85.2 \%$ (density of berry pulp). Trait indicators in the obtained clusters are presented in Table 1.

Table 1. Clusters by trait values

\begin{tabular}{|l|c|c|c|}
\hline \multirow{2}{*}{ Trait } & \multicolumn{3}{c|}{ Clusters } \\
\cline { 2 - 4 } & 1 & 2 & 3 \\
\hline Number of berries, pcs/plant & 53.90 & 65.66 & 89.08 \\
\hline Maximum width of the berry of $\mathrm{I}^{\text {th }}$ order, mm & 26.64 & 33.94 & 37.90 \\
\hline Height of the berry of the $\mathrm{I}^{\mathrm{h}}$ order, mm & 28.40 & 36.61 & 38.64 \\
\hline Average berry weight for all collections, g & 12.03 & 15.72 & 16.28 \\
\hline Average weight of the berry of $\mathrm{I}^{\mathrm{th}}$ order, g & 19.70 & 27.54 & 29.91 \\
\hline Yield, g/plant & 667.80 & 1039.67 & 1367.99 \\
\hline Berry pulp density, g & 295.66 & 384.77 & 749.00 \\
\hline
\end{tabular}

The maximum indicators of economically valuable characteristics of crop structure and berry pulp density are observed in the third cluster, which includes the "ideal variety" and the hybrid 5-18-15 Onda $\times$ Belrubi, which indicates the high genotypic value of this number in terms of a set of characteristics for further breeding work on the development of new strawberry varieties.

Varieties and hybrids from the second cluster, which united the majority of the studied samples, may also have a breeding perspective for further work on the garden strawberry crop. High values of the berry size of $\mathrm{I} \underline{\mathrm{th}}$ order, average weight of the berries and biological yield indicate in favor of their breeding value.

The low values of the considered traits in the varieties and hybrids included in the first cluster indicate a relatively low genotypically determined adaptive potential of these forms under the appropriate growing conditions.

The breeding and genetic potential of varieties and hybrid forms with their participation is closely related to the inheritance features of both individual traits and the entire set of parameters that quantitatively characterize the studied strawberry genotypes features. In our work, the Euclidean distances from the "ideal" to the varieties and hybrids, calculated in the space of principal components, were used to estimate the inheritance of a complex of traits that determines the breeding and genetic potential and the proximity of genotypes to each other by the similarity of reactions to growing conditions. The obtained values of Euclidean distances from 1.63 to 8.64 were grouped into three intervals according to the number of clusters (Table 2).

Table 2. Groups of Euclidean distances from strawberry varieties and hybrids to the "ideal variety"

\begin{tabular}{|l|c|c|}
\hline \multicolumn{1}{|c|}{ Varieties and hybrids } & $\begin{array}{c}\text { Intervals of } \\
\text { Euclidean distances }\end{array}$ & Group \\
\hline "Ideal variety", 5-18-15 Onda $\times$ Belrubi, 5-19-15 Onda $\times$ Belrubi & $0-2.13$ & I \\
\hline $\begin{array}{l}\text { Nelli, 18-1-15 Belrubi } \times \text { Onda, 11-1-15 Belrubi } \times \text { Florence, 20-1-15 Onda } \\
\times \text { Elizabeth II, 35-13-15 Belrubi } \times \text { Florence, 13-1-15 Florence } \times \text { Belrubi, 5- } \\
\text { 17-15 Onda } \times \text { Belrubi, 35-12-15 Belrubi } \times \text { Florence, 14-1-15 Belrubi } \times \\
\text { Florence, 35-11-15 Belrubi } \times \text { Florence, Onda, Florence, 10-1-15 Belrubi } \times \\
\text { Nelli, Marmolada }\end{array}$ & $3.40-5.44$ & II \\
\hline $\begin{array}{l}\text { Elizabeth II, 2-14-08 Malling Pandora } \times \text { Marmolada, 5-5-08 Malling } \\
\text { Pandora } \times \text { Marmolada, Belrubi, 1-12-15 Belrubi } \times \text { Florence, Malling } \\
\text { Pandora, 1-11-08 Selva } \times \text { Belrubi, 1-1-08 Selva } \times \text { Marmolada }\end{array}$ & $6.55-8.64$ & III \\
\hline
\end{tabular}


The inherited mutual proximity of the studied varieties and hybrids, which characterizes their breeding and genetic potential, is observed in all the groups obtained, according to the variation series of Euclidean distances from the minimum to the maximum value.

The most numerous is the $2^{\text {nd }}$ group, which includes 15 varieties and hybrid selections. In addition to the varieties Onda and Florence, it includes most hybrids with their participation as parental forms, the exceptions are 5-18-15 Onda $\times$ Belrubi, 5-19-15 Onda $\times$ Belrubi, included in the first group and 1-12-15 Belrubi $\times$ Florence, represented in the third group.

Taking into account the fact that the content of groups for the intervals of Euclidean distances almost completely repeats the composition of the obtained clusters according to the Ward method, it is possible to interpret the entry of selections 5-18-15 and 5-19-15 from one combination of Onda and Belrubi crosses into one group with an ideal variety as the presence of a hereditary potential of genetic donors in the parent varieties Onda and Belrubi with their mutual combination. In favor of the donor genetic potential of the Belrubi variety, the combination of the majority of hybrid selections with its participation in the $1^{\text {st }}$ and $2^{\text {nd }}$ groups, which are closest to the "ideal variety" in terms of the maximum values of economically valuable traits, also testifies.

The good breeding value of the Nelli variety of local breeding is evidenced by its mutual entry with the hybrid selection of $10-1-15$ Belrubi $\times$ Nelli in the $2^{\frac{\text { nd }}{2}}$ group.

The Marmolada and Malling Pandora varieties have a relatively low selection and genetic potential, as evidenced by the combination of all hybrid forms with their participation in the $3^{\text {rd }}$ group, the most distant from the "ideal variety".

\section{Conclusions}

Based on the conducted research using the methods of multidimensional mathematical statistics, it was found that the most significant breeding and genetic potential for a complex of economically valuable characteristics of the crop structure and berry quality is possessed by the strawberry varieties Onda, Belrubi and Florence. Hybrid selections with their participation have a high breeding prospect in the development of new varieties of garden strawberry adapted to the region conditions. The selection and genetic significance is also represented by the Nelly variety of local selection.

\section{References}

1. S.D. Vieira, D.C. de Souza, I.A. Martins, G.H.M.R. Ribeiro, L.V. Resende, A.K.L. Ferraz, A.G. Galvão, J.T.V. de Resende, Genet. Mol. Res., 16(1), 1 (2017)

2. A. Masny, S. Masny, E. Żurawicz, K. Pruski, W. Mądry, Euphytica, 213(112), 1 (2016)

3. S. Ciulca, N. Carp, E. Madoşa, A. Ciulca, R. Şumălan, Not. Bot. Horti. Agrobo, 45(2), 517 (2017)

4. M. Sturzeanu, M. Călinescu, C. Nicola, I. Titirică, M. Ciucu, Fruit Grow. Res., 34, 57 (2018)

5. C. Cocco, S. Magnani, M.L. Maltoni, I. Quacquarelli, M. Cacchi, L.E.C. Antunes, L.F. D’Antuono, W. Faedi, G. Baruzzi, J. Berry Res., 5, 145(2015)

6. A.F. da Costa, L.P. Ribeiro, P.E. Ttodoro, L.L. Bhering, F.D. Tardin, M.J. Fornazier, H. Costa, D. dos Santos Martins, J.S.Z. Junior, Biosci. J. (Uberlândia), 34(1), 129 (2018)

7. P. Lucchi, G. Baruzzi, W. Faedi, Zbornik radova V savetovanja «Inovacije u voćarstvu», 33 (2015) 
8. R. González-Domínguez, A. Sayago, I. Akhatou, Á Fernández-Recamales, Foods, 9(1), 96, 1(2020)

9. B. Mezzetti, F. Balducci, F. Capocasa, C.-F. Zhong, R. Cappelletti, L. Di Vittori, L. Mazzoni, F. Giampieri, M. Battino, Int. J. Fruit Sci., 16, 194 (2016)

10. D. Ulrich1, K. Olbricht, J. Appl. Bot. Food Qual., 89, 223(2016)

11. A. Gabriel, J.T.V. de Resende, A.R. Zeist, L.V. Resende, N.C.V. Resende, R.A. Zeist, Hortic. bras., 37(1), 75(2019)

12. M. Mancini, L. Mazzoni, F. Gagliardi, F. Balducci, D. Duca, G. Toscano, B. Mezzetti, F. Capocasa, Foods, 9(4), 441, 1(2020)

13. D.M. Lambrecht, A.D. Lúcio, M.I. Diel, D. Schmidt, F. de L. Tartaglia, A.L. Tischler, Int. J. Innov. Educ. Res., 8(06), 136 (2020)

14. J.L.T. Chiomento, E.P.L. Júnior, M. D’Agostini, F.S. De Nardi, T. dos S. Trentin, A.G. Dornelles, J. Huzar-Novakowiski, E.O. Calvete, Sci. Hortic., 279, 1(2021)

15. A. Kassambara, Practical Guide To Principal Component Methods in, 2(STHDA, 2017) 